\title{
OPEN A late-surviving stem-ctenophore from the Late Devonian of Miguasha (Canada)
}

\begin{abstract}
Christian Klug ${ }^{1}$, Johanne Kerr², Michael S. Y. Lee ${ }^{3,4}$ \& Richard Cloutier ${ }^{5 \square}$
Like other soft-bodied organisms, ctenophores (comb jellies) produce fossils only under exceptional taphonomic conditions. Here, we present the first record of a Late Devonian ctenophore from the Escuminac Formation from Miguasha in eastern Canada. Based on the 18-fold symmetry of this discshaped fossil, we assign it to the total-group Ctenophora. Our phylogenetic analyses suggest that the new taxon Daihuoides jakobvintheri gen. et sp. nov. falls near Cambrian stem ctenophores such as 'dinomischids' and 'scleroctenophorans'. Accordingly, Daihuoides is a Lazarus-taxon, which post-dates its older relatives by over $\mathbf{1 4 0}$ million years, and overlaps temporally with modern ctenophores, whose oldest representatives are known from the Early Devonian. Our analyses also indicate that the fossil record of ctenophores does not provide strong evidence for or against the phylogenomic hypothesis that ctenophores are sister to all other metazoans.
\end{abstract}

Palaeozoic sediments yield a growing number of fossil invertebrates with radial symmetries, some being quite enigmatic with body plans differing radically from those of extant organisms. Ctenophores (comb jellies) are one of the phylogenetically most important and controversial metazoan groups, and interest in their fossil record has been catalysed by new records of spectacularly preserved materials from Cambrian Lagerstätten from the 518-million-years-old Chengjiang Biota ${ }^{1-8}$, the 505-million-years-old Burgess Shale ${ }^{9-11}$ and other Burgess Shalelike deposits ${ }^{12,13}$

Ctenophores have long been known to be near the base of Metazoa ${ }^{14}$, but some genetic and genomic studies have recently proposed that they are the most basal metazoans ${ }^{15-21}$, the 'ctenophores first' hypothesis. This has found some morphological support in a tentative Late Proterozoic stem-group representative of the ctenophores sensu lato $^{22}$. Nevertheless, this phylogenetic hypothesis has been challenged; several molecular studies now favour the traditional morphologically-based arrangement where sponges are sister group to all other animals ${ }^{23-28}$.

Here, we present an invertebrate fossil from the Late Devonian Escuminac Formation (Miguasha, Quebec, Canada), a UNESCO world heritage site famous for its abundance of well-preserved vertebrate fossils including most major evolutionary groups of Devonian lower vertebrates from jawless fish to stem-tetrapods ${ }^{29-38}$. Based on morphological similarities of this Canadian fossil with stem-ctenophore fossils from the Cambrian Lagerstätte of the Chinese locality Chengiiang 7,39, we assess its affinity to stem-group ctenophores ('dinomischids', Siphusauctum, 'scleroctenophorans $s^{1,3,7,13}$ ) and early crown group ctenophores. Modern ctenophores and many fossil forms lack mineralized hard parts, which renders the rare fossils that have been extracted from several Lagerstätten quite remarkable. Like the soft bodies of jellyfish and the polyps of hydrozoans and anthozoans, the probability for such soft bodies (or body regions) to become fossilized is extremely low. In spite of this low preservation potential, remains of stem-ctenophores have become known from several Cambrian and younger conservation deposits, and with even older candidate ctenophores in the Ediacaran ${ }^{22}$. While Cambrian Lagerstätten yielded several genera, ctenophore remains are much rarer in the Devonian; we are aware of only two studies, describing material from the German Hunsrück Slate ${ }^{40,41}$. This Early Devonian material, however, appears to belong to crown ctenophores morphologically similar to living forms such as Pleurobrachia, unlike the stem Cambrian taxa and the new Devonian stem taxon described here.

The most basal stem ctenophores are the 'dinomischids': sessile benthic petaloid invertebrates, many of which are equipped with a stalk. This group first was described from the Middle Cambrian Burgess Shale ${ }^{9}$. Based on the genus Dinomischus ${ }^{9}$, these early stalked forms were commonly called 'dinomischids'. According to Zhao et al.

${ }^{1}$ Paläontologisches Institut und Museum, Universität Zürich, Karl-Schmid-Strasse 4, 8006 Zurich, Switzerland. ${ }^{2}$ Parc national de Miguasha, 231 Route de Miguasha Ouest, Nouvelle, OC GOC 2E0, Canada. ${ }^{3}$ College of Science and Engineering, Flinders University, Adelaide, SA, Australia. ${ }^{4}$ Earth Sciences Section, South Australian Museum, Adelaide, SA, Australia. ${ }^{5}$ Département de Biologie, Chimie et Géographie, Université du Québec à Rimouski, 300 allée des Ursulines, Rimouski, OC G5L 3A1, Canada. ${ }^{\circledR}$ email: richard_cloutier@uqar.ca 

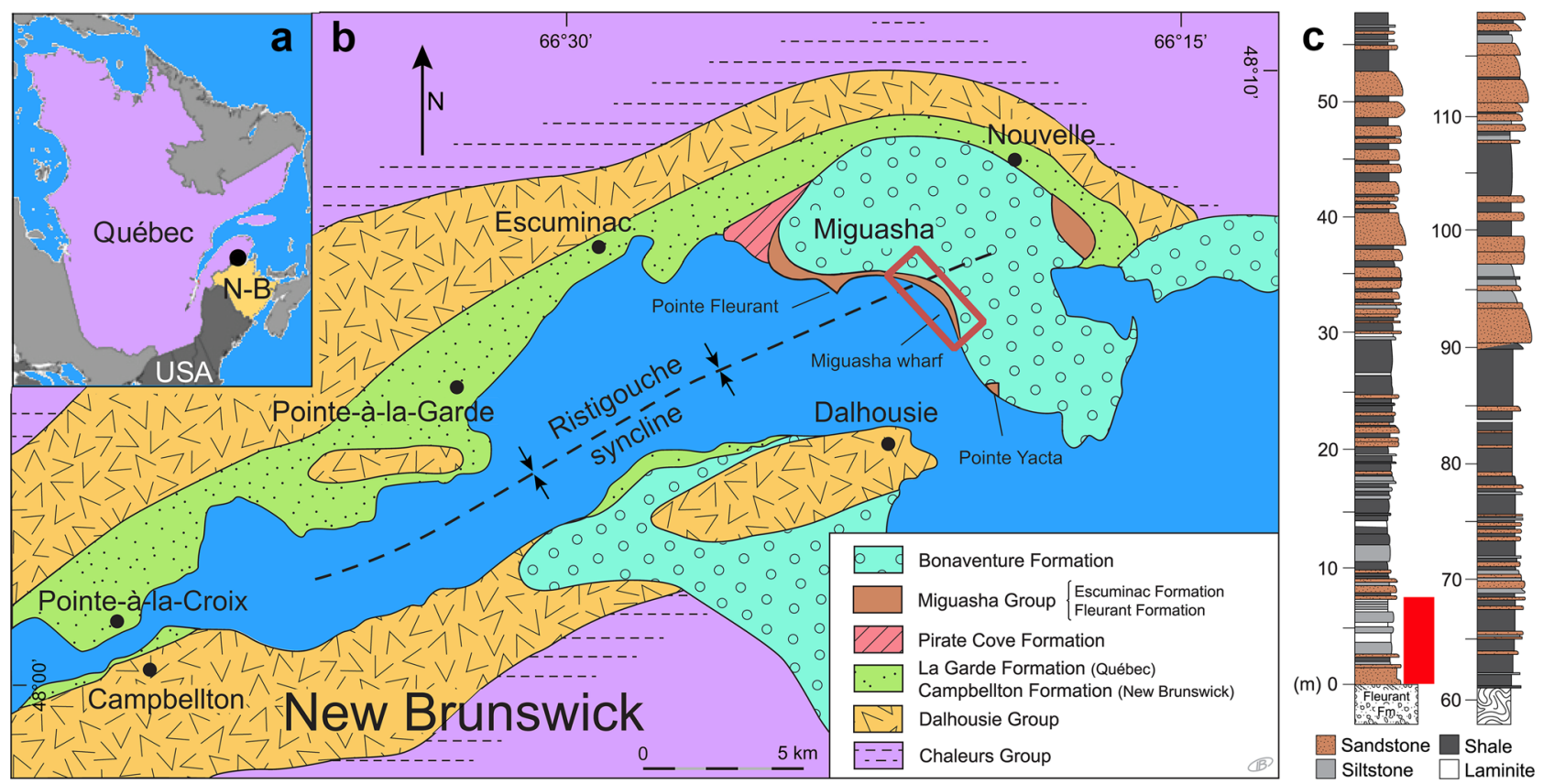

Figure 1. Geographic, geological and stratigraphic context of the Escuminac Formation. (a) Localisation of Miguasha in eastern Québec, Canada. (b) Geological map of the Escuminac Formation along the Ristigouche River, eastern Québec, Canada. (c) Simplified stratigraphic section of the Escuminac Formation showing the potential occurrence of Daihuoides jakobvintheri gen. et sp. nov. indicated by a red bar. Map and section modified from Cloutier et al. ${ }^{29,30}$.

(Ref : 1113), dinomischids "form a grade in the lower part of the ctenophore stem group" and include taxa such as Xianguangia, Daihua, and Dinomischus that have hexaradiate-based symmetry (e.g., sixfold, 18-fold). Some later, skeletonised stem-ctenophores were termed 'Scleroctenophora' (Zhao et al. ${ }^{7}$ : fig. 6; 'scleroctenophorans' have a shorter stalk, lack the 'petals' and have no bracts and might be monophyletic: Ou et al. ${ }^{5}$ ). To date, all known dinomischids and scleroctenophorans are Cambrian. Remarkably, analysis of the material described here suggests it is a very late-surviving member of this part of the ctenophore tree, occurring in strata over a hundred million years younger with no intervening known record, thus making it a Lazarus taxon with an extensive ghost lineage. The morphological similarities to Cambrian forms and the mix of characters regarding overall shape and symmetries render this discovery important. The aims of this study are to (1) describe the only known specimen of this Devonian ctenophore, (2) discuss its phylogenetic and systematic position, and the impact of fossil data for ctenophore affinities, and (3) assess its palaeoecological role.

\section{Results}

Geological setting. The middle Frasnian ${ }^{34}$ (Late Devonian) Escuminac Formation, exposed on the south coast of the Gaspe Peninsula (eastern Quebec), is $119 \mathrm{~m}$ thick and forms steep cliffs up to $30 \mathrm{~m}$ high along the coast (Fig. 1). Five lithofacies are recognized ${ }^{30}$ : rare coarse conglomerates $(<0.1 \%$ of total thickness), gray-green sandstones (25\% of total thickness), carbonate-rich siltstones (22\% of total thickness), shales ( $46 \%$ of total thickness), and thin shale-siltstone laminites (7\% of total thickness). Konservat and Konzentrat Fossil-Lagerstätten horizons occur in the transgressive phase of the five sequences within an inner wave-dominated estuary ${ }^{30}$. The formation includes four depositional environments ${ }^{30}$ : braided fluvial conglomerates, intertidal siltstones and argillites, bay head delta sandstones and siltstones, and central semi-enclosed basin shales.

Taphonomy. Specimen MHNM 24-01 is on the surface of a 3-4 cm thick, greyish-greenish fine siltstone bed with laminar, $1-\mathrm{cm}$ thick graded beddings. Cubic pyrite crystals (Fig. 2a) and minute plant debris are present near the specimen. The specimen is only moderately deformed by sediment compaction. Anatomical details are preserved as elevations and furrows as well as hematite-stained surfaces. The precise stratigraphic position is unknown; the specimen was collected on the beach along the Miguasha cliff within the limits of the Miguasha National Park. Sedimentology and sediment colour suggest that the specimen came from the lower units of the Escuminac Formation.

Because of the gross similarity between jellyfish (Cnidaria) and comb jellies (Ctenophora), one might expect similar taphonomical conditions for their fossilisation. Young and Hagadorn ${ }^{40}$ reviewed the taphonomy of cnidarian medusae through their complete fossil record. Among the optimal preservation conditions, they reported the absence of bioturbation and rarity of scavengers, anoxic or hypoxic environment, rapid sediment burial, in sandy coasts, estuarine-lagoonal setting, mud-dominated open marine shelf. All these conditions are encountered for the occurrence of Daihuoides in fine-grained siltstone likely coming from the lower section of the Escuminac Formation. 

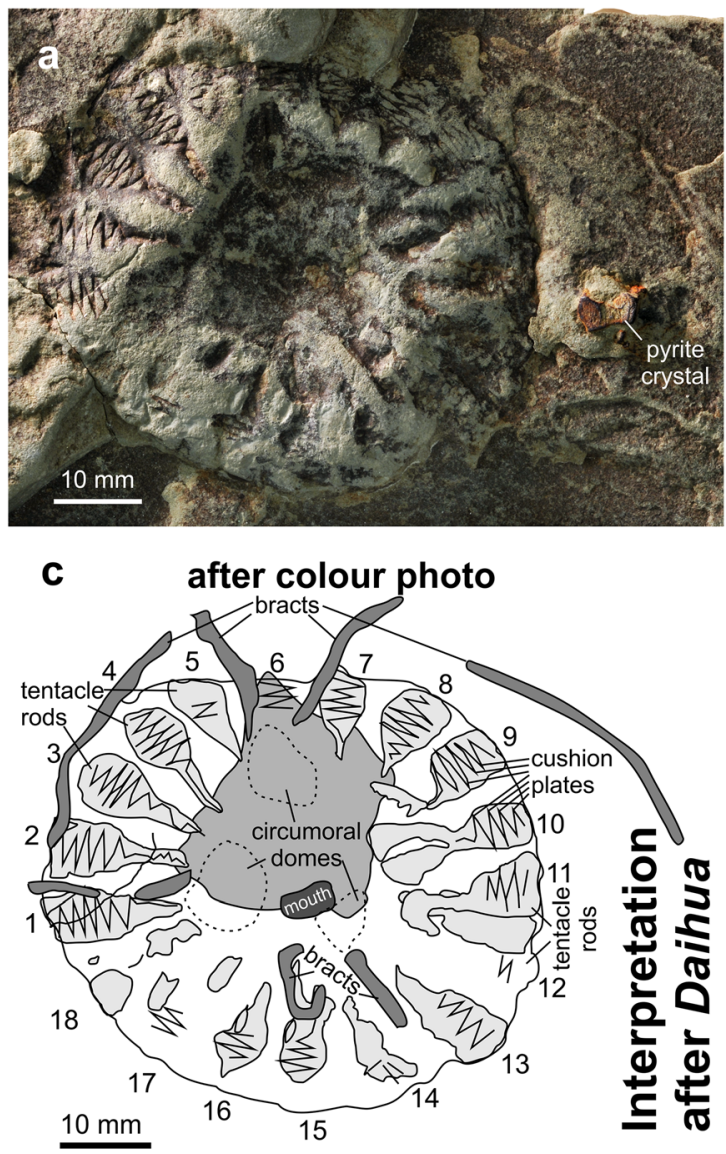

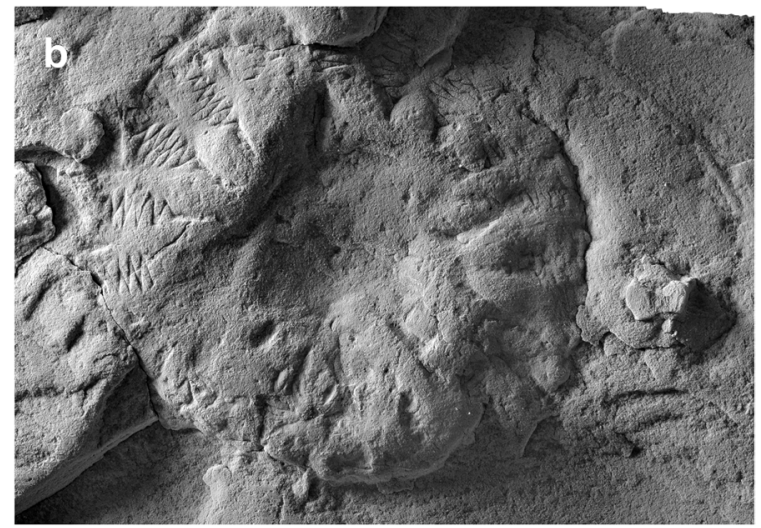

d after b/w-photo with $\mathrm{NH}_{4} \mathrm{Cl}$

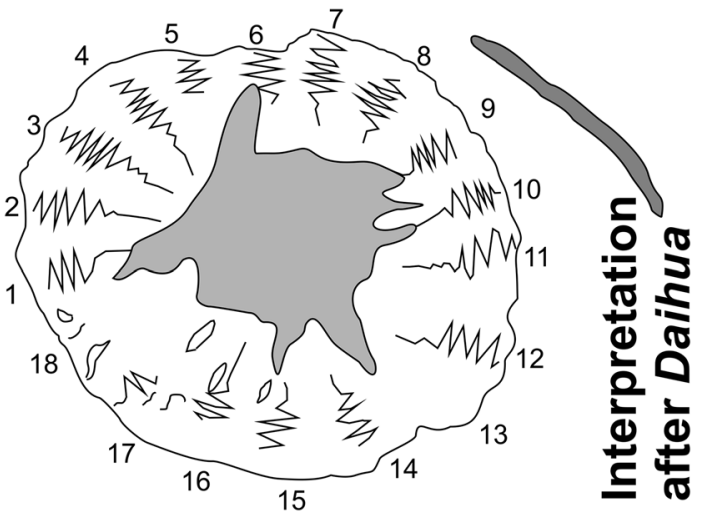

f

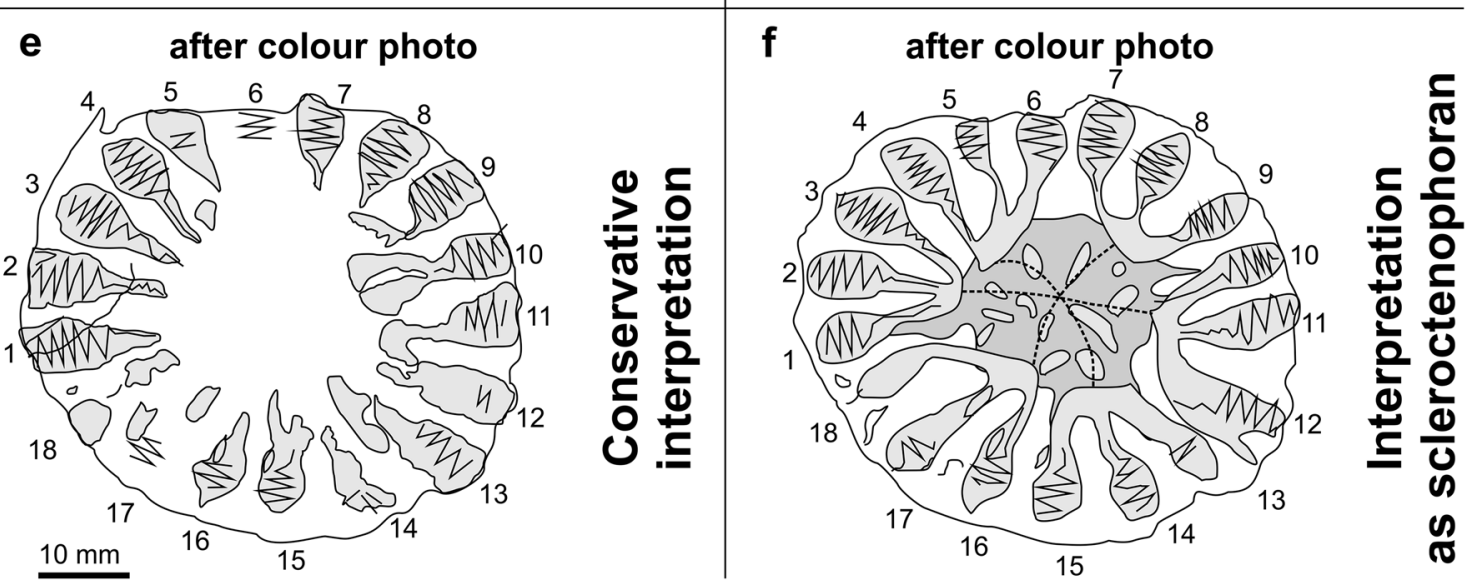

Figure 2. Photos and drawings of Daihuoides jakobvintheri n. gen. et sp. Holotype, MHNM 24-01,

Escuminac Formation, Late Devonian, Miguasha. (a) color photo. (b) specimen coated with $\mathrm{NH}_{4} \mathrm{Cl}$. (c-f)

drawings after (a,b); light grey—tentacle rods, middle grey—oral surface, dark grey-bracts. Drawings of $D$. jakobvintheri $\mathrm{n}$. gen. et sp. based on three alternative interpretations: (c, d) interpretation based on Daihua, (e) conservative interpretation, and (f) interpretation as a scleroctenophoran.

Faunal assemblage. In contrast to the early vertebrate diversity (20 species), the described invertebrate fauna (12 species) is relatively depauperate including only a few aquatic and continental taxa ${ }^{29,30}$. The aquatic component of the invertebrate fauna includes the abundant spinicaudatan Asmusia membranacea ${ }^{32}$ and extremely rare remains of a parastylonurid eurypterid ${ }^{33}$ as well as a scolecodont annelid ${ }^{34}$. The continental component, similarly rare, includes the millipede Zanclodesmus willett $i^{35}$, the scorpion Petaloscorpio bureaui, and a gigantoscorpionid ${ }^{33}$. Fragments of arthropod cuticles, some of them likely referable to arachnids or trigonotarbids ${ }^{30}$, have been found in palynological preparations ${ }^{34}$. Two aquatic ichnotaxa (Gyrophyllites and Planolites montanus) $)^{36,37}$ have been identified, as well as two types of undescribed trace fossils ${ }^{30}$; ichnofossils and bioturbation are extremely rare thought the Escuminac Formation ${ }^{29,30}$. Until now, typical marine invertebrates were totally absent, a fact, which led earlier researchers ${ }^{38}$ to interpret the Miguasha palaeoenvironment as fresh- 
water lakes. It is worth mentioning that we are not aware of any fully freshwater species of ctenophores, both living and fossil. Palynological ${ }^{34}$, geochemical ${ }^{41,42}$, sequential stratigraphy ${ }^{30}$ and vertebrate assemblage ${ }^{43}$ evidence suggest an estuarine setting with potential connectivity to a coastal marine environment.

Systematic palaeontology. Metazoa

Total-group Ctenophora

Comment: In some characters (18 tentacle rods, alternating cushion plates), the only specimen of the new taxon resembles the Cambrian stem-ctenophore Daihua from the Early Cambrian of Chengjiang, China (Zhao et al. ${ }^{7}$ : Fig. 2A). The 18-fold symmetry also occurs in other Cambrian genera (Dinomischus and Xianguangia ${ }^{7}$ ), thereby further supporting a stem position. Similarly, our phylogenetic analyses (based on the character matrix of Zhao et al. ${ }^{7}$ ) places Daihuoides gen. nov. on the ctenophoran stem, above the Cambrian dinomischids but below scleroctenophorans. The taxon is very different to the Early Devonian ctenophores from the Hunsrück Slate ${ }^{44,45}$, which are crown forms similar to living Pleurobranchia.

Daihuoides gen. nov.

Type species. Daihuoides jakobvintheri sp. nov.

Etymology: After Daihua, a stem-ctenophoran described by Zhao et al. ${ }^{7}$, referring to morphological similarities (thus the ending-oides) to the holotype of D. sanqiong, the only species of the genus Daihua.

Diagnosis. A large stem-group ctenophore with 18 radii carrying tentacles, which surround the oral surface/ the central body axis. The calyx has a circular outline and carries 18 comb rows or tentacle rods with cushion plates arranged in a zigzag pattern. The comb rows or tentacle rods widen outward from the mouth and then taper again towards the edge of the calyx. Within this portion, the comb rows or tentacle rods carry ca. 10 larger, alternating cushion plates.

Comments. The only specimen shows only one end of the body, and due to taphonomic compression, it is uncertain whether this is the aboral (dorsal) or oral (ventral). This interpretation is further hampered by the possibility that the body might have collapsed, projecting the oral surface onto the aboral surface. In any case, several characters such as calyx shape, presence or absence of a stalk and morphological details of the tentacles are unknown. Additionally, the holotype of Daihuoides jakobvintheri gen. et sp. nov. is preserved in a fine-grained siltstone; thus, although some anatomical detail is discernible, the preservation differs profoundly from those of Cambrian occurrences, which are embedded in much finer grained claystones. Nevertheless, the overall similarity such as the presence of 18 tentacle rods (Fig. 2) and possibly three oral domes are here considered adequate to include near stem-group ctenophores (e.g., 'dinomischids') sensu Zhao et al. .

We name the Devonian genus Daihuoides after the Cambrian genus Daihua referring to its similarity in the arrangement of structures resembling tentacle rods (Zhao et al. ${ }^{7}$ : Fig. 2A) and the zigzag appearance of the possible cushion plates (Zhao et al. ${ }^{7}$ : Fig. 2E). Among all the illustrations of Cambrian 'dinomischids', it is Daihua, which shows the greatest degree of resemblance enabling the homologisation of several organs.

The only other stem ctenophore showing a high degree of resemblance is Ctenorhabdotus. This genus lacks a stalk. It has a subspherical calyx with eight partitions on the surface that branch into three comb rows each (Conway Morris and Collins ${ }^{10}$ : figs. 23, 24). Accordingly, there are 24 rows, six more than in Daihuoides gen. nov. However, depending how one interprets the visible structures in the Escuminac specimen, one could infer a grouping into three comb rows (Fig. 2f). Notably, both 18 and 24 represent multiples of planes of symmetries commonly occurring in ctenophorans and cnidarians, namely four and six.

The new taxon differs from all Palaeozoic taxa in the alternating arrangement of comb rows or cushion plates. Also, the short tentacle rods or comb rows do not resemble the conditions seen in Cambrian stem-ctenophores. The unique combination of characters, and its huge stratigraphic separation from similar taxa (Cambrian), justifies placing it in a new genus.

Daihuoides jakobvintheri sp. nov.

Etymology. Honouring Jakob Vinther (University of Bristol) for his substantial contributions on soft-bodied organisms from the Early Palaeozoic, which are still understudied.

Holotype. MHNM 24-01.

Nomenclatural statement. A Life Science Identifier (LSID) was obtained for the new genus and species (Daihuoides jakobvintheri): urn:lsid:zoobank.org:act: D3DF39BB-5794-4842-A833-655DD72A1F76, and for this publication: urn:lsid:zoobank.org: pub: 93A203AA-B0EA-42A2-8295-AD07B85E1359.

Material: Holotype specimen MHNM 24-01.

Locality, horizon and age. Miguasha, Quebec, Canada; Escuminac Formation, middle Frasnian, Devonian.

Diagnosis. Same as genus definition, due to monotypy.

Description. Depending on the morphological and taxonomic interpretation, the holotype MHNM 24-01 is exposed from the oral or the aboral side. It is disc-shaped with a roughly circular outline; the calyx has a diameter of $58.2 \mathrm{~mm}$. It carries a circular bulge that is $17.8 \mathrm{~mm}$ wide, surrounding a central depression of approximately $20 \mathrm{~mm}$ diameter. This depression is largely stained by iron oxides, which cover an irregular surface of about $28 \mathrm{~mm}$ in diameter (middle grey in Fig. 2c). This surface has some roughly radially arranged projections giving it a star-shaped outline. Micro-CT scan analysis did not reveal any internal anatomical detail.

The bulge surrounding this depression carries 18 club-shaped fields that are arranged radially. Although these fields are quite strongly eroded in some places, all show remains of deeply incised, haematite-stained zigzag-lines (Fig. 2). The amplitude of the single bends reaches $7.6 \mathrm{~mm}$ in the broadest part of the field and becomes strongly reduced towards the centre of the oral surface (Fig. 3). In the broader part of the club-shaped fields ('tentacle 

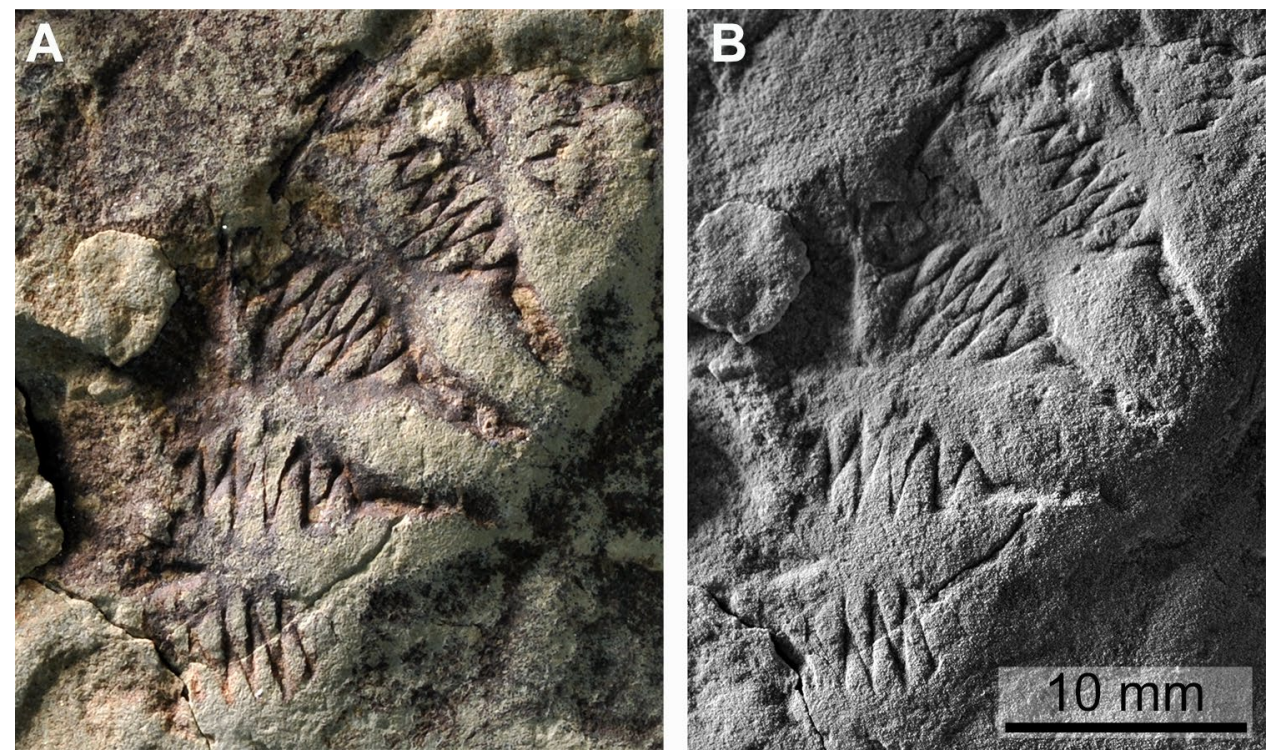

Figure 3. Morphological details of Daihuoides jakobvintheri n. gen. et sp. Holotype, MHNM 24-01, Escuminac Formation, Late Devonian, Miguasha. (A) color photo showing the tentacle rods/ cushion plates. (B) same as in (A) but specimen coated with $\mathrm{NH}_{4} \mathrm{Cl}$.

rods' or 'comb fields'?), about ten such bends can be seen. The single fields alternate and the zigzags are pointed in both directions. The narrow furrow first reduces the intensity of its curvature and then fades out inward. The club-shaped field is slightly longer than the furrow. Additional furrows and impressions are somewhat irregular and two alternative interpretations are discussed below.

\section{Discussion}

The holotype of Daihua sanqiong shows 18 elongate tentacle rods, the elongate tips of which protrude far beyond the disc-shaped body. In addition, the oral surface carries three circumoral domes, which, in typical ctenophores, give rise to a pair of long tentacles termed bracts by Zhao et al. ${ }^{7}$. The number of 'tentacle rods' and the arrangement of cushion plates on them is similar in Daihuoides gen. nov., but the oral surface is quite irregular and unequivocal interpretations are impossible without better preserved material. With only 18 rays, any symmetry in the central structure must have been hexameral or triradiate. Perhaps this surface encompassed the three oral domes (dashed lines in Fig. 2c), which would measure about $10 \mathrm{~mm}$ in width, if that interpretation is correct. In turn, this interpretation is linked with the presence of 1-2 mm wide furrows (dark grey in Fig. 2c), partially filled with iron oxides, which extend from the tentative circumoral domes; accordingly, these furrows might represent remains of the bracts. Another tentative bract extends outside of the calyx (top right in Fig. 2a-d). A depression measuring 4 times $6 \mathrm{~mm}$ is interpreted with reservation as mouth according to its position between the supposed circumoral domes.

Although the Burgess Shale form Ctenorhabdotus ${ }^{10}$ differs from Daihuoides gen. nov. in possessing 24 versus 18 radii, they share tentacles that do not extend beyond the disc, and similar connections between comb rows ${ }^{10}$. Some specimens of Ctenorhabdotus display a central structure showing the tetrameral symmetry; the four initial rays branch again into eight, which then lead to three comb-rows each. We interpreted the fossil accordingly in Fig. 2f, but these connections between comb rows are arguable (Figs. 2c-e, 3). When comparing Daihuoides gen. nov. to published specimens of Ctenorhabdotus ${ }^{7}$, it is also conceivable that we see the comb rows arranged in groups of three around the apical organ. In Fig. 4, we show alternative reconstructions as benthic and planktic forms with spherical to flattened circular body form.

We performed parsimony and Bayesian phylogenetic analyses using a character-by-taxon matrix based on Zhao et al. ("Methods" section). The consensus trees of these analyses places Daihuoides gen. nov. mid-way along the stem leading to crown-group Ctenophora (Fig. 5; see Figs. S1-S4). Its inclusion in the crown-group appears unlikely because of its symmetry and its benthic habitat (most modern taxa are planktic; the only recent benthic group, the Platyctenida, has a quite different morphology and usually measures less than $10 \mathrm{~mm}^{46}$. In an earlier study by Ou et al. (Ou et al. ${ }^{5}$ : fig. 4), the living Beroida is the sister taxon to all other (fossil and recent) ctenophores, thereby placing all fossil forms in the crown-group. However, Zhao et al. ${ }^{7}$ retrieved a much-reduced crown-group, and this arrangement is replicated in our study (as would be expected). However, contrary to Zhao et al. ${ }^{7}$, the fossil evidence does not increase support for a ctenophore-cnidarian (coelenterate) clade: this hypothesis remains supported by four or five steps over the ctenophores-first hypothesis, whether fossils are included or excluded (Methods).

Daihuoides gen. nov. appears to be a transitional taxon between the most basal stem ctenophores (the benthic 'dinomischids'), and higher stem ctenophores (such as scleroctenophorans, where stalks were reduced). It has the hexaradial-based symmetry of dinomischids, rather than the tetraradial-based symmetry of more crownward 

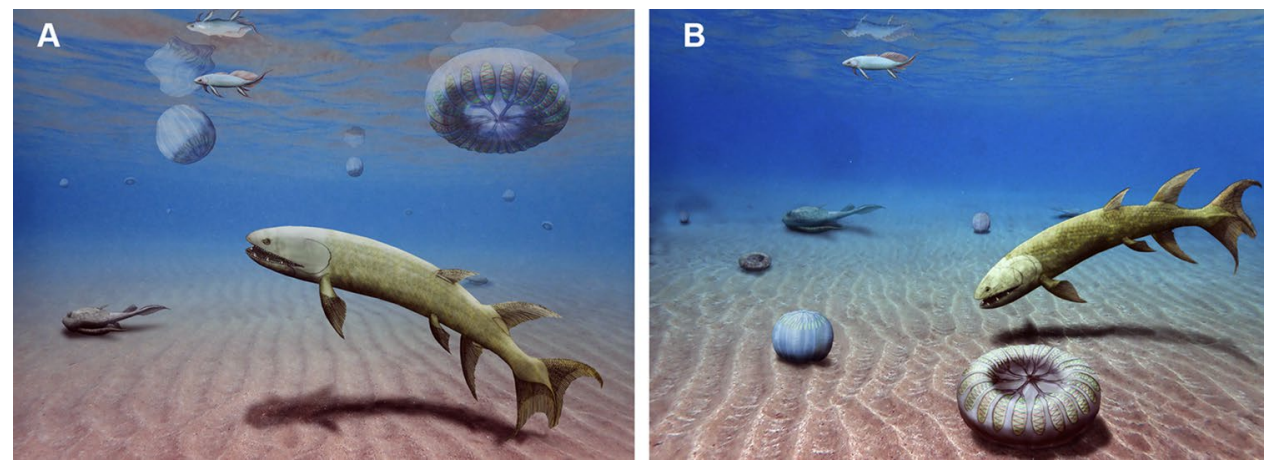

Figure 4. Reconstructions. Corresponding to its transitional position, we interpreted Daihuoides jakobvintheri n. gen. et sp. from the Devonian of Canada as a planktonic animal like many crown group comb jellies (A) or as benthic organism like 'dinomischids' (B). Note the alternative interpretations of the body shape as being either more disc-shaped or more spherical.
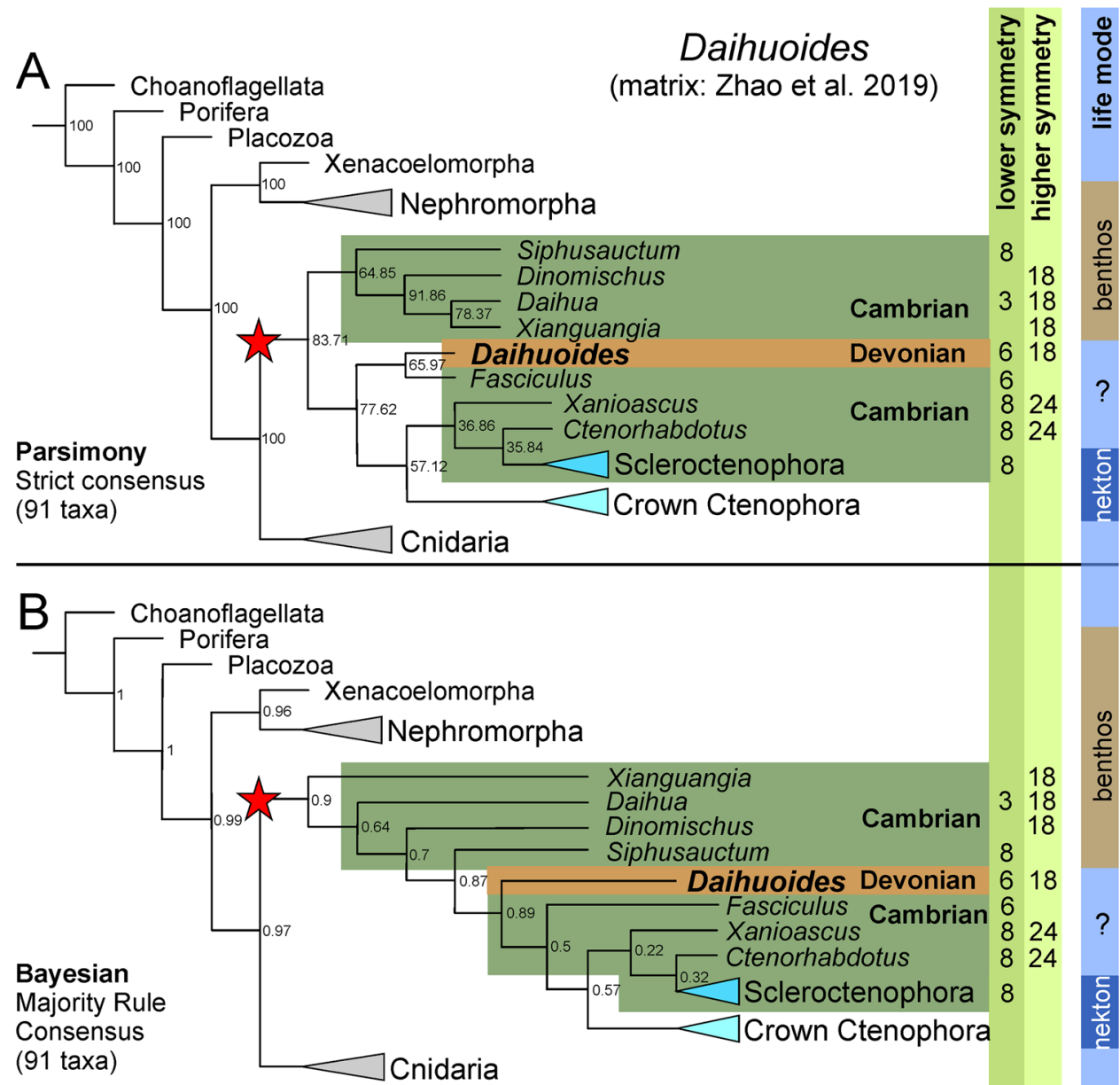

Figure 5. Phylogenies. Possible phylogenetic positions of Daihuoides based on data matrix derived from Zhao et al. ${ }^{7}$. For the character matrix and complete trees showing all taxa and details see the Supplementary Information. Note the distribution of higher and lower symmetries (light green fields) as well as the mode of life on the right (blue/brown fields). (A) Simplified strict consensus tree from parsimony analysis; numbers at nodes denote bootstrap percentages. (B) Simplified majority-rule consensus tree from Bayesian inference, numbers at nodes denote posterior probabilities. Star = total-group Ctenophora. Dark green colour on tree $=$ Cambrian taxa. Brown colour on tree $=$ Devonian (here only Daihuoides). 
ctenophores. However, it resembles crownward stem ctenophores such as Ctenorhabdotus in lacking distinct tentacles around a crown. It thus falls right in the middle of the ctenophore stem. Notably, however, all stem taxa immediately above and below Daihuoides gen. nov. are Cambrian: Daihuoides gen. nov. is thus more than 100 million years younger than all other taxa in that region of the tree. In turn, this implies that Ordovician and Silurian conservation deposits will sooner or later yield comparable stem ctenophorans, which will help to improve our understanding of the evolution of these early forms.

The most basal ctenophores ('dinomischids') were stalked benthic forms, while more crownward ctenophores have reduced stalks and are often entirely pelagic. The position of Daihuoides gen. nov. near the boundary of these two grades helps fill in a major gap in ctenophore evolution. The Devonian age of this fossil also provides important temporal continuity between these Cambrian stem-ctenophores and living Ctenophores. Notably, the fossil record of modern ctenophores extends at least to the Early Devonian, with forms very similar to living Pleurobrachia preserved in the Hunsrück slate (Pragian-Emsian). The presence of Daihuoides gen. nov. in the Late Devonian implies temporal overlap of Cambrian-type stem-ctenophores and modern ctenophores across much of the Devonian.

Accepting the position of Daihuoides gen. nov. as a late-surviving dinomischid, the Ctenophora exhibit a coherent picture of an evolution from sessile to planktic forms with a change in symmetry from a high number of radii ( 18 or 24 ) to a low multiple of 2 ( 4 or 8 ). The take-off from sediment is a recurrent feature in many clades happening in the early Palaeozoic. Living ctenophores are also predominantly marine, occasionally entering brackish habitats ${ }^{47}$. Brackish-marine salinities as likely prevailed in Miguasha ${ }^{41,42}$, raising the possibility that Daihuoides was also a brackish water taxon. However, it appears more plausible that this ctenophore was transported from the open sea into an estuary, which would also explain its scarcity; the presence of a scolecodont and acritarchs found in the lower section of the Escuminac Formation also suggested this marine connectivity ${ }^{30,34}$.

\section{Methods}

The specimen was photographed with a Nikon D-300 with an objective AF-S micro Nikkor 60 mm under white light both in colour and in black and white after it was coated with $\mathrm{NH}_{4} \mathrm{Cl}$-sublimate. It was scanned with a SkyScan using the following parameters: $130 \mathrm{kV}, 61 \mu \mathrm{A}, 0.25 \mathrm{~mm}$ brass filter, $5000 \mathrm{~ms}$ exposure time, 3684 projections with an angular step of $0.2^{\circ}$, voxel resolution of $35.54 \mu \mathrm{m}$. The $3 \mathrm{D}$ reconstruction was made using NRecon (Bruker micro CT, 2016) and generated Tiff (16 bytes) images. Drishti Import and Drishti 2.6.4 and 2.6.5 (beta version) were used for manual segmentation of the specimen ${ }^{45,48}$.

We carried out phylogenetic analyses using by adding the new taxon, and one new character, to the characterby-taxon matrix of Zhao et al. ${ }^{7}$, resulting in a matrix of 94 taxa and 279 characters. The codings for the new taxon and character states are available in Appendix 1, and the full matrices are available as executables (see below).

We performed both phylogenetic analyses using both parsimony and Bayesian methods. Following Zhao et al. ${ }^{7}$, all characters were treated as unordered, Choanoflagellata were the outgroup, and analyses used the full matrix (94 taxa), as well as a reduced matrix (91 taxa, 3 contentious Ediacaran taxa deleted).

Parsimony analyses used PAUP ${ }^{\star} 4.0 \mathrm{a} 168^{49}$, the following settings were used to ensure all tree islands were sampled, but large islands did not clog up all memory: $<$ HSEARCH addseq $=$ random nreps $=500$ rstatus $=$ yes nchuck $=1000$ chuckscore $=1$ enforce $=$ no; $>$. Executable files with all these settings (and other relevant settings) are in SI Appendix 2. The strict and majority-rule consensus trees for the 94 taxon and 91 taxon analyses are shown in Figs. S1-S2. Node support was assessed with 200 nonparametric bootstrap replicates, and these values are shown in Fig. S3.

Bayesian analyses used MrBayes 3.2.7 $7^{50}$, with rate variability across characters was accommodated using a gamma parameter. Each analysis used 4 runs (each with 4 chains and heating temperature of 0.1 ), with 20 million generations and a burning of 0.25 . Stationarity was confirmed across runs with PSRF close to 1 and standard deviations of split (clade) frequencies very close to 0. Executable files are in SI Appendix 3. The majority-rule consensus trees are shown in Fig. S4.

To evaluate whether the addition of fossil ctenophores support for the Ctenophoran-Cnidarian clade, we compared the lengths of the best unconstrained trees (which grouped ctenophorans and cnidarians), and the best trees which placed ctenophorans as basal to all other metazoans as per genomic studies. These competing topologies were compared using data matrices which included only living taxa, and living taxa + fossils (this approach was performed using both the unmodified Zhao et al.'s ${ }^{7}$ matrix, and the present matrix). Using the Zhao et al's matrix, when only 77 extant taxa were considered, the basal position of ctenophorans entailed an extra 4 steps (382 vs. 378 steps). When all fossil taxa were included (93 taxa), the basal position of ctenophorans entailed 5 steps (426 vs. 421 ); when the 3 contentious fossil forms were excluded (90 taxa), this changed to 4 steps (421 vs. 417). We repeated this approach with our slightly expanded matrix, with identical results: with 77 extant taxa, the difference was 4 steps ( 385 vs. 381 ), with all 94 living and fossil taxa, it was 5 steps ( 437 vs. 432 ), and with 91 living and non-contentious fossil taxa, the difference was 4 steps (431 vs. 427). Executable files for topology tests are in Appendix 4.

The fossil record therefore does not increase support for ctenophores having cnidarian affinities, relative to an alternative basal metazoan position. The difference between these hypotheses remains at 4 or 5 steps, whether fossils are excluded or included.

\section{Data availability}

Specimen MHNM 24-01 is curated in the collections of the Musée d'Histoire naturelle de Miguasha (MHNM), parc national de Miguasha. Data sets generated during the current study, including raw tiff stacks from $\mu \mathrm{CT}$ analyses are available from the corresponding authors on reasonable request. Data matrices, list of characters, 
and PAUP/MrBayes executables and trees are available as supplementary information (Appendices 1-4 and Figs. S1-S4).

Received: 5 March 2021; Accepted: 6 September 2021

Published online: 24 September 2021

\section{References}

1. Chen, J.-Y., Hou, X.-G. \& Lu, H.-Z. Early Cambrian hock glass-like rare sea animal Dinomischus (Entoprocta) and its ecological features. Acta Palaeontol. Sin. 28, 58-71 (1989).

2. Chen, J.-Y. et al. Raman spectra of a lower Cambrian ctenophore embryo from southwestern Shaanxi, China. Proc. Natl. Acad. Sci. U.S.A. 104, 6289-6292 (2007).

3. Peng, J., Zhao, Y.-L. \& Lin, J. P. Dinomischus from the middle Cambrian Kaili Biota, Guizhou, China. Acta Geol. Sin. 80, 498-501 (2006).

4. Han, J. et al. Tiny sea anemone from the Lower Cambrian of China. PLoS ONE 5, e13276 (2010).

5. Ou, Q. et al. A vanished history of skeletonization in Cambrian comb jellies. Sci. Adv. 1, e1500092 (2015).

6. Ou, Q. et al. Three Cambrian fossils assembled into an extinct body plan of cnidarian affinity. Proc. Natl. Acad. Sci. U.S.A. 114, 8835-8840 (2017).

7. Zhao, Y. et al. Cambrian sessile, suspension feeding stem-group ctenophores and evolution of the comb jelly body plan. Curr. Biol. 29, 1112-1125 (2019).

8. Daley, A. C. \& Antcliffe, J. B. Evolution: The battle of the first animals. Curr. Biol. 29, R241-R264 (2019).

9. Conway Morris, S. A new entoproct-like organism from the Burgess Shale of British Columbia. Palaeontology 20, 833-845 (1977).

10. Conway Morris, S. \& Collins, D. Middle Cambrian ctenophores from the Stephen Formation, British Columbia. Canada. Philos. Trans. R. Soc. Lond. B Biol. Sci. 351, 279-308 (1996).

11. O’Brien, L. J. \& Caron, J.-B. A new stalked filter-feeder from the middle Cambrian Burgess Shale, British Columbia, Canada. PLoS ONE 7, e29233 (2012).

12. Mikulas, R. \& Kordule, V. A problematic fossil from the Middle Cambrian of the Barrandian area (Czech Republic). J. Geosci. (Prague) 43, 187-190 (1998).

13. Kimmig, J., Strotz, L. C. \& Lieberman, B. S. The stalked filter feeder Siphusauctum lloydguntheri $\mathrm{n}$. sp. from the middle Cambrian (Series 3, Stage 5) Spence Shale of Utah: Its biological affinities and taphonomy. J. Paleontol. 91, 902-910 (2017).

14. Wallberg, A., Thollesson, M., Farris, J. S. \& Jondelius, U. The phylogenetic position of the comb jellies (Ctenophora) and the importance of taxonomic sampling. Cladistics 20, 558-578 (2004).

15. Dunn, C. W. et al. Broad phylogenomic sampling improves resolution of the animal tree of life. Nature 452, 745-749 (2008).

16. Philippe, H. et al. Phylogenomics revives traditional views on deep animal relationships. Curr. Biol. 19, 706-712 (2009).

17. Rokas, A. My oldest sister is a sea walnut?. Science 342, 1327-1329 (2013).

18. Ryan, J. F. et al. The genome of the ctenophore Mnemiopsis leidyi and its implications for cell type evolution. Science 342, e1242592 (2013).

19. Moroz, L. L. et al. The ctenophore genome and the evolutionary origins of neural systems. Nature 510, 109-114 (2014).

20. Halanych, K. M., Whelan, N. V., Kocot, K. M., Kohn, A. B. \& Moroz, L. L. Miscues misplace sponges. Proc. Natl. Acad. Sci. U.S.A. 113, E946-E947 (2016).

21. Halanych, K. M. The ctenophore lineage is older than sponges? That cannot be right! Or can it?. J. Exp. Biol. 218, 592-597 (2015).

22. Tang, F., Bengtson, S., Wang, Y., Wang, X. L. \& Yin, C. Y. Eoandromeda and the origin of Ctenophora. Evol. Dev. 13, 408-414 (2011).

23. Pick, K. S. et al. Improved phylogenomic taxon sampling noticeably affects nonbilaterian relationships. Mol. Biol. Evol. 27, 19831987 (2010).

24. Pisani, D. et al. Genomic data do not support comb jellies as the sister group to all other animals. Proc. Natl. Acad. Sci. U.S.A. 112, 15402-15407 (2015).

25. Pisani, D. et al. Reply to Halanych et al.: Ctenophore misplacement is corroborated by independent datasets. Proc. Natl. Acad. Sci. U.S.A. 113, E948-E949 (2016).

26. Feuda, R. et al. Improved modeling of compositional heterogeneity supports sponges as sister to all other animals. Curr. Biol. 27, 3864-3870 (2017).

27. Simion, P. et al. A large and consistent phylogenomic dataset supports sponges as the sister group to all other animals. Curr. Biol. 27, 958-967 (2017).

28. Kapli, P. \& Telford, M. J. Topology-dependent asymmetry in systematic errors affects phylogenetic placement of Ctenophora and Xenacoelomorpha. Sci. Adv. 6, eab5162 (2020).

29. Cloutier, R. Great Canadian Lagerstätten 4. The Devonian Miguasha biota (Québec): UNESCO World heritage site and a time capsule in the early history of vertebrates. Geosci. Can. 40, 149-163 (2013).

30. Cloutier, R., Proust, J.-N. \& Tessier, B. The Miguasha Fossil-Fish-Lagerstätte: A consequence of the Devonian land-sea interactions. Palaeobiodivers. Palaeoenviron. 91, 293-323. https://doi.org/10.1007/s12549-011-0058-0 (2011).

31. Cloutier, R. et al. Elpistostege and the origin of the vertebrate hand. Nature 579, 549-554. https://doi.org/10.1038/s41586-0202100-8 (2020).

32. Martens, T. In Devonian Fishes and Plants of Miguasha, Quebec, Canada (eds Schultze, H.-P. \& Cloutier, R.) 112-113 (Verlag Dr. Friedrich Pfeil, 1996).

33. Jeram, A. J. In Devonian Fishes and Plants of Miguasha, Quebec, Canada (eds Schultze, H.-P. \& Cloutier, R.) 103-111 (Verlag Dr. Friedrich Pfeil, 1996).

34. Cloutier, R., Loboziak, S., Candilier, A.-M. \& Blieck, A. Biostratigraphy of the Upper Devonian Escuminac Formation, eastern Quebec, Canada: A comparative study based on miospores and fishes. Rev. Palaeobot. Palynol. 93, 191-215 (1996).

35. Wilson, H. M., Daeschler, E. B. \& Desbiens, S. New flat-backed archipolypodan millipedes from the Upper Devonian of North America. J. Paleontol. 79, 738-744 (2005).

36. Maples, C. G. In Devonian Fishes and Plants of Miguasha, Québec, Canada (eds Schultze, H.-P. \& Cloutier, R.) 114-119 (Verlag Dr. Friedrich Pfeil, 1996).

37. Schultze, H.-P. In Intertidal Fishes: Life in Two Worlds (eds Horn, M. H. et al.) 373-392 (Academic Press, 1999).

38. Dineley, D. L. \& Williams, B. P. F. In Symium-Continental Sedimentation in Northeastern North America (ed. Klein, G. V.) 241-264 (Geological Society of America, 2021).

39. Chen, J.-Y. \& Erdtmann, B.-D. In The Early Evolution of Metazoa and the Significance of Problematic Taxa (eds Simonetta, A. M. \& Conway Morris, S.) 57-76 (Cambridge University Press, 1991).

40. Young, G. A. \& Hagadorn, J. W. Evolving preservation and facies distribution of fossil jellyfish: a slowly closing taphonomic window. Boll. Soc. Paleontol. Ital. 59, 185-203 (2020).

41. Schmitz, B., Åberg, G., Werdelin, L., Forey, P. \& Bendix-Almgreen, S. E. ${ }^{87} \mathrm{Sr} /{ }^{86} \mathrm{Sr}, \mathrm{Na}, \mathrm{F}, \mathrm{Sr}$, and La in skeletal fish debris as a measure of the paleosalinity of fossil-fish habitats. Geol. Soc. Am. Bull. 103, 786-794 (1991). 
42. Matton, O., Cloutier, R. \& Stevenson, R. Apatite for destruction: Isotopic and geochemical analyses of bioapatites and sediments from the Upper Devonian Escuminac Formation (Migiasha, Québec). Palaeogeogr. Palaeoclimatol. Palaeoecol. 361-362, 73-83 (2012).

43. Schultze, H.-P. \& Cloutier, R. (eds) Devonian Fishes and Plants of Miguasha (Canada. Verlag Dr. Friedrich Pfeil, Québec, 1996).

44. Stanley, G. D. \& Stürmer, W. The first fossil ctenophore from the lower devonian of West Germany. Nature 303, 518-520 (1983).

45. Stanley, G. D. \& Stürmer, W. A new fossil ctenophore discovered by X-rays. Nature 328, 61 (1987).

46. Glynn, P. W. et al. Benthic ctenophores (Platyctenida: Coeloplanidae) in South Florida: Predator-prey interactions. Inverteb. Biol. 137, 133-150. https://doi.org/10.1111/ivb.12212 (2018)

47. Costello, J. H., Bayha, K. M., Mianzan, H. W., Shiganova, T. A. \& Purcell, J. E. Transitions of Mnemiopsis leidyi (Ctenophora: Lobata) from a native to an exotic species: A review. Hydrobiologia 690, 21-46. https://doi.org/10.1007/s10750-012-1037-9 (2012).

48. Limaye, A. in Proceedings of SPIE-Developments in X-Ray Tomography VIII. (ed S.R. Stock).

49. Swofford, D. L. PAUP*: Phylogenetic Analysis Using Parsimony ( ${ }^{\star}$ and other methods_). Version 4 (Sinauer Associates, Sunderland, 2003).

50. Ronquist, F. et al. MrBayes 3.2: efficient Bayesian phylogenetic inference and model choice across a large model space. System. Biol. 61, 539-542 (2012).

\section{Acknowledgements}

Nathaniel Bertrand Maltais (Rimouski) photographed the holotype and performed the micro-CT scan. Gabriel Aguirre Fernandez, Torsten Scheyer and Stephan Spiekman (all Zürich) helped with earlier phylogenetic analyses. This article is a contribution to the research project Nr. 200020_184894 funded by the Swiss National Science Foundation (C.K.) and a Discovery Grant (2019-06133) by the Natural Sciences and Engineering Research Council of Canada (R.C.).

\section{Author contributions}

C.K., R.C. and J.K. conceived the project. C.K. prepared the illustrations. R.C. supervised the image processing including computerized tomography restorations. M.L. and C.K. conducted the phylogenetic analyses. C.K., M.L. and R.C. discussed the results and prepared the manuscript, with input from J.K. All authors read, corrected and approved of the final manuscript version.

\section{Competing interests}

The authors declare no competing interests.

\section{Additional information}

Supplementary Information The online version contains supplementary material available at https://doi.org/ 10.1038/s41598-021-98362-5.

Correspondence and requests for materials should be addressed to R.C.

Reprints and permissions information is available at www.nature.com/reprints.

Publisher's note Springer Nature remains neutral with regard to jurisdictional claims in published maps and institutional affiliations.

(c) (i) Open Access This article is licensed under a Creative Commons Attribution 4.0 International License, which permits use, sharing, adaptation, distribution and reproduction in any medium or format, as long as you give appropriate credit to the original author(s) and the source, provide a link to the Creative Commons licence, and indicate if changes were made. The images or other third party material in this article are included in the article's Creative Commons licence, unless indicated otherwise in a credit line to the material. If material is not included in the article's Creative Commons licence and your intended use is not permitted by statutory regulation or exceeds the permitted use, you will need to obtain permission directly from the copyright holder. To view a copy of this licence, visit http://creativecommons.org/licenses/by/4.0/.

(C) The Author(s) 2021 